\title{
Effects of SEA0400 on Ouabain-induced Arrhythmias in Guinea Pigs
}

\author{
M. S. Amran ${ }^{1,2}$, N. Homma ${ }^{1}$, and K. Hashimoto ${ }^{1}$ \\ ${ }^{1}$ Department of Pharmacology, Interdisciplinary Graduate School of Medicine and Engineering, \\ University of Yamanashi, Shimokato 1110, Tamaho, Yamanashi-409-3898, Japan \\ ${ }^{2}$ Department of Pharmaceutical Chemistry, Faculty of Pharmacy, University of Dhaka, Dhaka-1000, \\ Bangladesh
}

Received 25 May 2011, accepted in final revised form 20 October 2011

\begin{abstract}
The sodium-calcium exchange (NCX) is one of the major regulators of intracellular $\mathrm{Ca}^{2+}$ concentration in cardiac myocytes. The effects of NCX blockers as antiarrhythmic agents are still controversial. We investigated antiarrhythmic effects of SEA0400 (SEA), a novel NCX inhibitor, on ouabain-induced arrhythmias in guinea pigs. In the whole animal arrhythmia model, we observed effects of SEA on the ouabain-induced arrhythmia using ECG recordings. In the isolated myocyte, we observed action potential configurations and oscillations due to calcium overload using the current clamp method. In the whole animal model, SEA at a dose range of 1-10 mg/kg (intravenous, bolus) suppressed ouabain-induced arrhythmias dose-dependently. In isolated ventricular myocytes, SEA $(0.1-3 \mu \mathrm{M})$ suppressed ouabain-induced oscillatory activity observed between action potentials. SEA (0.1-3 $\mu \mathrm{M})$ also suppressed ouabain-induced NCX current $\left(I_{\mathrm{NCX}}\right)$ that is also called transient inward current $\left(I_{\mathrm{TI}}\right)$. Our results indicate that NCX is involved in arrhythmia and oscillatory activity induced by ouabain. The inhibition of these arrhythmias and oscillatory activity by SEA might result from the inhibition of NCX.
\end{abstract}

Keywords: $\mathrm{Na}^{+}-\mathrm{Ca}^{2+}$ exchange (NCX); SEA0400; NCX inhibitors; current clamp; ECG.

(c) 2012 JSR Publications. ISSN: 2070-0237 (Print); 2070-0245 (Online). All rights reserved.

doi:10.3329/jsr.v4i1.7722 J. Sci. Res. 4 (1), 213-225 (2012)

\section{Introduction}

Digitalis is known to have positive inotropic (therapeutic) and arrhythmogenic (toxic) effects. The receptor for digitalis is $\mathrm{Na}^{+-} \mathrm{K}^{+-}$ATPase, and its inhibition results in the depletion of $\left[\mathrm{K}^{+}\right]_{\mathrm{i}}$, accumulation of $\left[\mathrm{Na}^{+}\right]_{\mathrm{i}}$ followed by $\left[\mathrm{Ca}^{2+}\right]_{\mathrm{i}}$ overload. Ouabain, a rapidly acting digitalis, induces triggered pacemaker type arrhythmias. The $\mathrm{Ca}^{2+}$ overload due to the inhibition of $\mathrm{Na}^{+}$pump induces oscillatory $\mathrm{Ca}^{2+}$ release from sarcoplasmic reticulum (SR) and oscillatory fluctuation in the resting potential. An ionic current associated with

\footnotetext{
${ }^{2}$ Corresponding author: amdshah_69@yahoo.com
} 
this $\mathrm{Ca}^{2+}$ oscillation has been named 'transient inward current $\left(I_{\mathrm{TI}}\right)^{\prime}$. It has been reported that about $75 \%$ of $I_{\mathrm{TI}}$ is attributed to an ionic current generated by the forward mode operation of NCX because $I_{\mathrm{TI}}$ is known to develop under $\mathrm{Ca}^{2+}$ overload in cardiac cells [1$3]$, while the remaining current is mediated through (voltage-gated $\mathrm{Ca}^{2+}$ channels and other) non-specific cation channels.

NCX inhibitors such as SEA0400 (SEA) and KB-R7943 (KBR) have been developed recently, and it has been reported that SEA is more potent and selective than KBR [20-21, 25]. Since KBR has additional effects on $\mathrm{Ca}^{2+}$ channels, $\mathrm{Na}^{+}$channels and $\mathrm{K}^{+}$channels at concentrations used to inhibit NCX, the question arises as to its usefulness as a proper pharmacological tool for selective inhibition of NCX. To elucidate the involvement of NCX in the ouabain-induced arrhythmias we tried to explore the effects of SEA on the ouabain-induced oscillatory activity in single cardiac myocyte and arrhythmias of whole guinea pig models.

\section{Materials and methods}

The animal experiments were approved by the animal experimentation committee of the University of Yamanashi Interdisciplinary Graduate School of Medicine and Engineering, and animals were obtained through the Animal Laboratory for Research of this university.

\section{Ouabain-induced arrhythmias in the whole guinea pigs}

Guinea pigs weighing 300-400 g were anesthetized with sodium pentobarbital (50 mg/kg, intraperitoneal, i.p.). Respiration was maintained with artificial ventilation (under room air, volume $1.5 \mathrm{ml} / 100 \mathrm{~g}$, rate 55 strokes/ min) through the cannula in the trachea to maintain ${ }_{\mathrm{P}} \mathrm{CO}_{2}, \mathrm{P}_{2}$ and $\mathrm{pH}$ within the normal range. Polyethylene tubing was inserted into the right jugular vein to administer ouabain and other drugs. The left carotid artery was cannulated to monitor systemic blood pressure. Blood pressure, heart rate and ECG (Lead I and II) were continuously monitored using a polygraph (NEC san-ei Instruments Ltd., Tokyo, Japan). After 15 min of stabilization, the vehicle or SEA was administered as an i.v. bolus injection to different groups (i.e., control or $0-10 \mathrm{mg} / \mathrm{kg}$ ). Five min later, a bolus i.v. dose of $200 \mu \mathrm{g} / \mathrm{kg}$ of ouabain was injected to induce ventricular arrhythmias in the whole animal model, the dose of which had been reported to induce cardiac arrhythmias (PVC, VT and VF) (170 and $280 \mu \mathrm{g} / \mathrm{kg}$ ) [3] (Fig. 1, protocol I). In the case of posttreatment protocol, after $15 \mathrm{~min}$ stabilization, $200 \mu \mathrm{g} / \mathrm{kg}$ of ouabain were injected to induce ventricular arrhythmias. Five min later, vehicle or SEA was administered as an i.v. bolus injection (Fig. 1, protocol II).

Each animal received only one dose of SEA or the vehicle. The doses of SEA were $1-10 \mathrm{mg} / \mathrm{kg}$. Both pre- and post-treatments were found to be effective in preventing ouabain-induced arrhythmias.

\section{Isolation of cardiac myocytes}

The left ventricular myocytes of guinea pigs were enzymatically isolated using a standard 
procedure [4-6]. Briefly, guinea pigs weighing 300-400 g were anesthetized with pentobarbital (50mg/kg, i.p.) and sacrificed. The hearts were quickly removed and rinsed in calcium-free cold Tyrode solution. Using a Langendorff retrograde apparatus, 0.2 $\mathrm{mg} / \mathrm{ml}$ collagenase (type-I, Worthington, Lakewood, NJ, USA) or, $0.03 \mathrm{mg} / \mathrm{ml}$ collagenase (Blendzyme-3, Roche, Mannheim, Germany) was perfused for $15-20$ minutes at $36 \pm 1{ }^{0} \mathrm{C}$. Left ventricular muscles were minced by scissors, dispersed with gentle agitation in KraftBrühe (KB) medium and filtered by a $200 \mu \mathrm{m}$-pore nylon mesh. Cells were stored in KB medium at room temperature until use. More than $80 \%$ of the myocytes were rod-shaped and viable and $65 \%$ of the total isolated myocytes were tolerant to $1.8 \mathrm{mM}$ extracellular calcium. Only cells exhibiting a rod-shaped morphology and no signs of membrane damage were used for the experiments. Once isolated, the cells were used up to 12 hours. Tyrode solution for isolation contained (in mM): $\mathrm{NaCl} 135, \mathrm{KCl} 5.4, \mathrm{NaH}_{2} \mathrm{PO}_{4} 11, \mathrm{MgCl}_{2}$ 2, glucose 20. Tyrode solution for perfusion (bath solution) contained (in $\mathrm{mM}$ ): $\mathrm{NaCl} 135$, $\mathrm{KCl}$ 5.4, $\mathrm{NaH}_{2} \mathrm{PO}_{4} 1$, HEPES (Na salt) 10, $\mathrm{MgCl}_{2} 1$, glucose 20 and $\mathrm{CaCl}_{2}$ 1.8. The $\mathrm{pH}$ was adjusted to 7.4 with $\mathrm{NaOH}$ in both solutions. The $\mathrm{KB}$ medium contained (in $\mathrm{mM}$ ): glutamate $\mathrm{K} 90$, taurine $10, \mathrm{KCl} 25, \mathrm{KH}_{2} \mathrm{PO}_{4} 20, \mathrm{MgCl}_{2}$ 3, glucose 10, and EGTA 0.1. The $\mathrm{pH}$ was adjusted to 7.25 with $\mathrm{KOH}$.
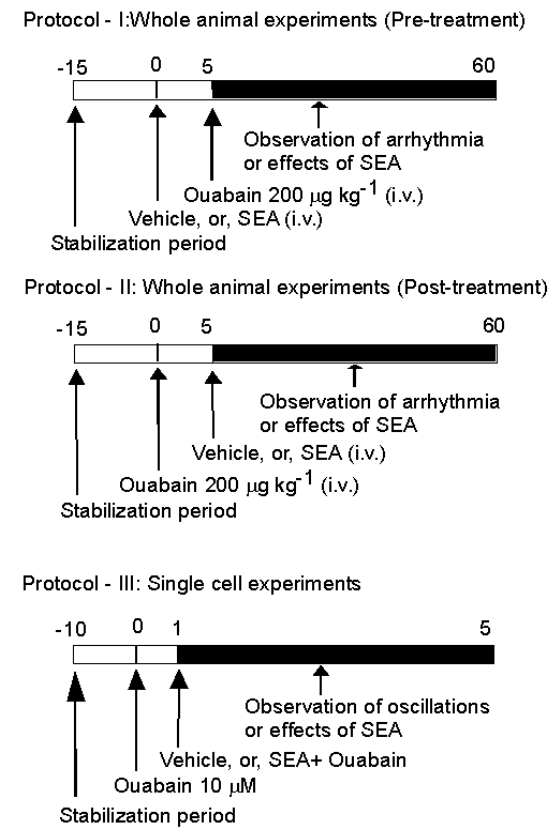

Fig. 1 Diagram of the experimental protocols used. Protocol-I and II was used in the whole animal experiments with pre- and post-treatment effects, Protocol-III was used for recordings of oscillations and action potentials in single cell experiments. The numbers above the bar indicate time (min). In protocol I, after stabilization, vehicle, or each dose of SEA was pre-treated. Then ouabain (200 $\mu \mathrm{g} / \mathrm{kg}$, i.v. bolus) was administered. The black column indicates the duration for observing arrhythmias. In protocol II, after stabilization, vehicle, or each dose of SEA was post-treated after ouabain injection. In protocol III, after stabilization, ouabain $(100 \mu \mathrm{M})$ was perfused first, then vehicle, or each dose of SEA was post-treated. 


\section{Electrophysiological recordings and Analysis}

Cell suspension was placed on a microscope groove and the bath solution was perfused for 10 min for stabilization of the cells. Cells exhibiting a rod-shaped morphology and no signs of membrane damage were selected. The microelectrode was carefully touched on the membrane of the selected cell and a giga seal was made by gentle suction through polyethylene tubing connected to a $1 \mathrm{ml}$ syringe. To induce electrical abnormality (such as arrhythmia in the whole animals), ouabain $(100 \mu \mathrm{M})$ dissolved in the bath solution was perfused. Oscillations appeared within one minute of perfusion of ouabain solution. In this stage, the vehicle (DMSO) or any dose of SEA (0.1-3 $\mu \mathrm{M})$ dissolved in the bath solution was simultaneously perfused with ouabain $(100 \mu \mathrm{M})$ to observe the effects on ouabaininduced oscillations (Fig. 1, protocol III). Each cell received only one dose of ouabain, and vehicle, or SEA. The temperature was maintained at $37{ }^{\circ} \mathrm{C}$.

A patch clamp amplifier (L/M-EPC7, LIST-MEDICAL ELECTRONIC, D-6100, Darmstadt, Germany) was used in the current-clamp and voltage clamp experiments for recording action potential (AP) configurations and NCX current $\left(I_{N C X}\right)$ or transient inward current $\left(I_{T I}\right)$ at extracellular $\mathrm{Ca}^{2+}$ concentration of $1.8 \mathrm{mM}$ [7]. Pipettes with 0.5-1.5 $\mathrm{M} \Omega$ resistance were made from alluminosilicate capillary glass using a programmable multistep puller (Sutter Medical, Navato, CA, USA). APs were evoked by injecting a depolarizing current $(0.5 \mathrm{~ms}, 1.25 \times$ threshold $)$ via the recording electrodes. NCX current was induced at $-40 \mathrm{mV}$ as the holding potential. Action potentials and NCX current tracings were displayed on the computer monitor and recorded (Nihon Kohden Corporation, Tokyo, Japan) (Fig. 1, protocol III). Pulse generation and data acquisition were controlled by pCLAMP software and by a running Compaq physio PC computer that was interfaced with Digidata 1200 interface (Axon Instruments, Foster city, CA, USA). The temperature was controlled by a bath temperature controller (DTC 300T, Dia Medical System Co. Ltd., Tokyo, Japan) and monitored on the microscope groove by Thermistor (Class 1.0, Shibaru Electronics Co. Ltd., Tokyo, Japan). The recording electrodes were filled with a solution containing (in mM): KCl 20, K-aspartate 120, Mg-ATP 5, HEPES (acid) 10. The $\mathrm{pH}$ was adjusted to 7.25 with $\mathrm{KOH}$.

\section{Measurement of amplitude and relative amplitude of oscillations}

The oscillations that have been seen in between action potential configurations in isolated ventricular myocytes were recorded as $\mathrm{mV}$ versus time (sec). To express those amplitudes (refer to Fig. 5d and 5e), we at first measured the height of amplitudes of each and every oscillation in between action potential configurations in millimeters ( $\mathrm{mm}$ ) and then expressed those values in percentage to get relative amplitude of oscillations.

\section{Chemicals and drugs}

SEA0400 was a kind gift from Taisho Pharmaceuticals Ltd., (Saitama, Japan) and was dissolved in a vehicle supplied by Taisho (a lipid emulsion containing 20\% soybean oil). Ouabain (Sigma) was dissolved directly in bath solution. All other chemicals were purchased from Sigma (St Louis, MO, USA) and Wako (Tokyo, Japan). 


\section{Data analysis and statistics}

Statistical analysis was based on the guidelines for statistics [8] and modified for the study of arrhythmias using guinea pig hearts [9-10]. Data were expressed as mean \pm S.E.M. Differences in mean values between experimental groups were analyzed by one way ANOVA (analysis of variance) followed by Dunnet's multiple comparison test where applicable. A probability value less than $0.01(p<0.01)$ was defined to be significant.

\section{Results}

\section{Effects of SEA on ouabain-induced arrhythmias in the whole animal model}

In the whole animal experiments with guinea pigs, the injection of ouabain $(200 \mu \mathrm{g} / \mathrm{kg}$, i.v. bolus) induced various types of ventricular tachyarrhythmias such as premature ventricular contraction (PVC), ventricular tachycardia (VT) and ventricular fibrillations (VF). Fig. 2a-h shows typical ECG tracings of normal sinus rhythm (NSR), PVC, VT and VF; and at the same time it shows the arterial blood pressure during VT, VF, and when VF returns to VT and vice versa, respectively. Fig. $2 \mathrm{~g}$ also shows how VF is transformed to VT and vice versa with consequence rise (Fig. 2h) and fall (to zero in case of VF, Fig. 2f) of blood pressure. Therefore, Arterial blood pressure was used as an indicator to depict this phenomenon which is unique in small animals with high heart rates (200-300 bpm).

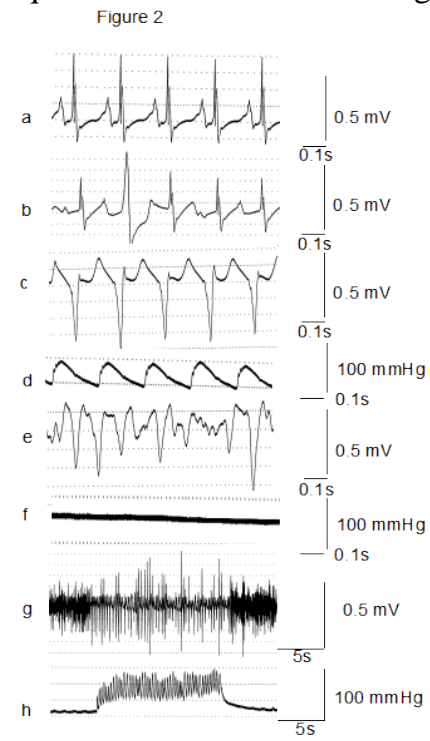

Fig. 2 Typical ECG tracings showing various types of ventricular tachyarrhythmias before (a) and after ouabain (200 $\mu \mathrm{g} / \mathrm{kg}$ ) (b-h). Panel (a) shows normal sinus rhythm (NSR), (b) premature ventricular contraction, (c) ventricular tachycardia, (d) Blood pressure during VT, (e) ventricular fibrillation, (f) blood pressure during VF, (g) VF turns to VT and vice versa, (h) blood pressure during 'VF turns to VT and vice versa'. The vertical line(s) indicates $0.5 \mathrm{mV}$ in panel a, b, c, e and g (ECG tracings for NSR, PVC, VT, VF and 'VF turns to VT and vice versa') and $100 \mathrm{mmHg}$ indicate blood pressure in panel d, $\mathrm{f}$ and h (ECG tracings for blood pressure under VT, VF and conversion of VT to VF and vice versa). The horizontal line indicates $100 \mathrm{~ms}(0.1 \mathrm{~s})$ in panel a, b, c, d, e and $\mathrm{f}$, and $5 \mathrm{~s}$ in panel $\mathrm{g}$ and $\mathrm{h}$. The recording speed from panel a-f is $100 \mathrm{~mm} / \mathrm{sec}$ and that of in panel g-h is $5 \mathrm{~mm} / \mathrm{sec}$. ECG tracings are chosen from one of the nine $(\mathrm{n}=9)$ similar and representative control experiments. NSR: normal sinus rhythm, PVC: premature ventricular tachycardia, VT: ventricular tachycardia, VF: ventricular fibrillation. 
Fig. 3a-c show the each type of arrhythmia with their duration of each phase in individual experiment induced by ouabain $(200 \mu \mathrm{g} / \mathrm{kg}$, i.v. bolus) and effects of pre- and post-treatment of SEA. Fig. 3a shows duration of time (min) for the various types of arrhythmias induced by ouabain and their frequent change from one state to another. It is also evident that the ouabain-induced fatal arrhythmias such as ventricular tachycardias (VT and VF) are also frequently transformed to ventricular fibrillations and vice versa. Fig. $3 \mathrm{~b}$ and 3c show the effects of pre- and post-treatment of SEA0400 on those arrhythmias in each experiment ( $\mathrm{n}=6$ for all groups). The most fatal form of arrhythmias, the VF, did not appear after both pre- and post-treatment of SEA in guinea pigs.
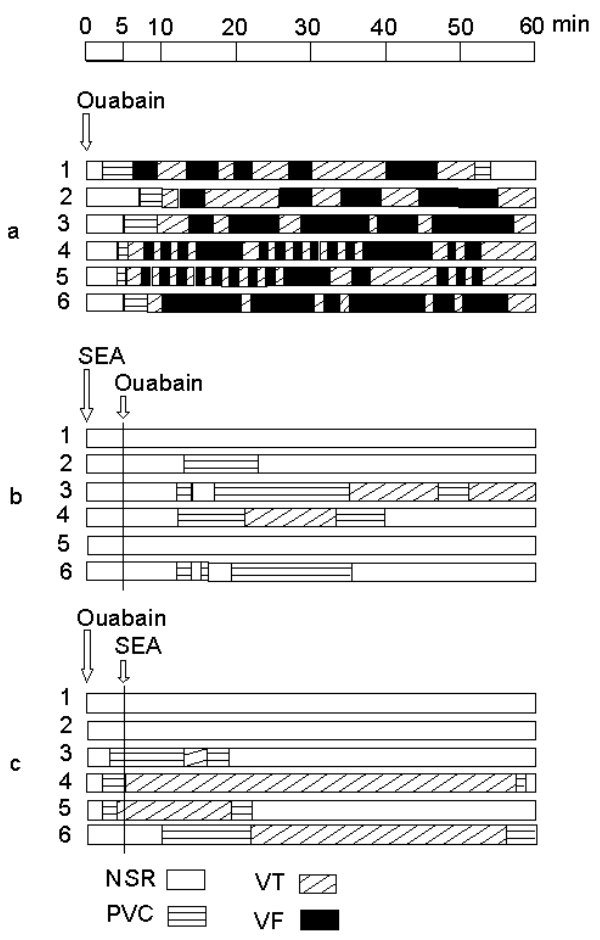

Fig. 3 Effects of pre- and post-treatment of SEA (10 mg/kg) on ouabain-induced arrhythmias in guinea pigs. Panel a shows control (200 $\mu \mathrm{g} / \mathrm{kg}$ of ouabain, or, $0 \mathrm{mg} / \mathrm{kg}$ of SEA), panel b shows pre-treatment of SEA and panel c shows post-treatment of SEA $(10 \mathrm{mg} / \mathrm{kg})$. In panel a, arrow indicates infusion of ouabain. In panel b, the first arrow indicates the infusion of SEA and the second arrow indicates the infusion of ouabain after 5 min of infusion of SEA. In panel c, the first arrow indicates infusion of oubain and the second arrow indicates the infusion of SEA after 5 min of infusion of ouabain. The bar at the front indicates time scale in min. Each bar in each panel indicates the responses of each guinea pig after infusion of ouabain and SEA, respectively. ( $\mathrm{n}=6$ for all groups). NSR: normal sinus rhythm, PVC: premature ventricular tachycardia, VT: ventricular tachycardia, VF: ventricular fibrillation, Pre-SEA: Pre-treatment of SEA, Post-SEA: Post-treatment of SEA.

Fig. 4 shows summarized effects of SEA0400 (pre-treatment, $1-10 \mathrm{mg} / \mathrm{kg}$ and posttreatment, only a single dose of $10 \mathrm{mg} / \mathrm{kg}$ was shown) on each arrhythmia. In the control 
condition, that is, in presence of ouabain (and without any NCX inhibitors), the duration of normal sinus rhythm (NSR), PVC, VT and VF were $6 \pm 2,3 \pm 2,22 \pm 7$ and $29 \pm 8$ (min), respectively. In the presence of SEA (during the pre-treatment, $10 \mathrm{mg} / \mathrm{kg}$ ) these duration of each arrhythmia was $43 \pm 18,11 \pm 10,6 \pm 9$ (min) and there was no occurrence of VF. During post-treatment of SEA (10 mg/kg) these duration was $37 \pm 24,6 \pm 6,17 \pm 22$ (min) and there was no occurrence of VF. Thus, both pre- and post-treatments of SEA prove to be effective in suppressing ouabain-induced arrhythmias in the whole animal model, although pre-treatment looks a little bit better to suppress VT (pre-treatment, $10 \mathrm{mg} / \mathrm{kg}$, $6 \pm 9$ (min) versus post-treatment, $10 \mathrm{mg} / \mathrm{kg}, 17 \pm 22$ (min).

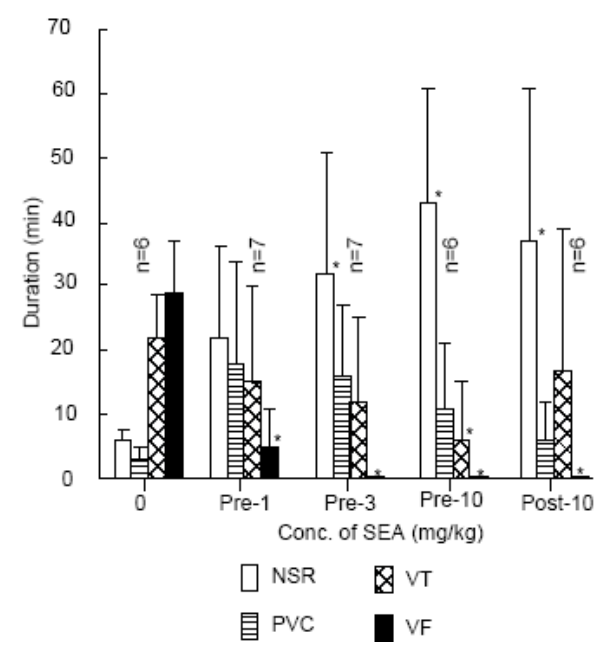

Fig. 4. Effects of SEA (0-10 mg/kg) on ouabain-induced ventricular arrhythmias including premature ventricular contraction (PVC), ventricular tachycardia (VT) and ventricular fibrillation (VF) in anesthetized guinea pigs. The sum of duration of each arrhythmia is plotted against the concentration of the drugs. Data are expressed as mean \pm S.E.M $(n=6-7)$. The significant change against control $(p<0.01)$ was shown by asterisk. NSR: normal sinus rhythm.

\section{Ouabain-induced oscillations in single ventricular myocytes and Effects of SEA on the ouabain-induced oscillations}

Natural course of action potential configurations and abnormal oscillatory activity (that is, oscillations in between action potential configurations) in isolated ventricular myocytes of guinea pigs induced by ouabain $(10 \mu \mathrm{M})$ were shown in Fig $5 \mathrm{a}$ and $\mathrm{b}$. These oscillations occurred within one minute after infusion of ouabain solution, gradually increasing in magnitude in a concentration-dependent manner (1-100 $\mu \mathrm{M}$, Fig. 5d).

To assess the contribution of reverse mode (Ca entry mode) of NCX on the abnormal oscillatory activity in between action potential configurations in isolated ventricular 
myocytes of guinea pigs induced by ouabain, we examined the effects of SEA (Fig. 5c) where almost no oscillation is visible. That is, SEA (0.1-3 $\mu \mathrm{M})$ concentrationdependently suppressed these oscillations (Fig. 5e) and the concentration of SEA required for $50 \%$ inhibition $\left(\mathrm{IC}_{50}\right.$ ) was calculated to be $75 \pm 3 \mathrm{nM}$ in our experiments with guinea pigs.
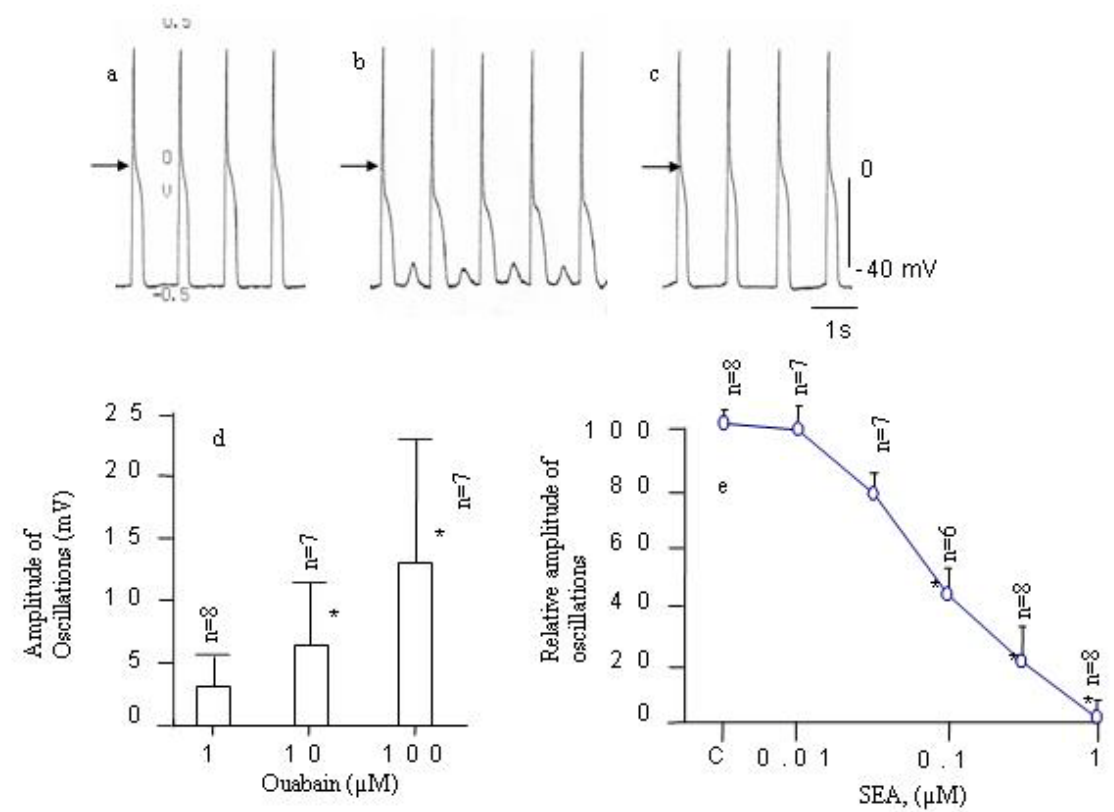

Fig. 5. Effects of SEA on ouabain-induced oscillatory activity in single ventricular myocytes recorded by current-clamp method. Panel (a) (b) and (c) show control, ouabain-induced oscillatory activity and effect of SEA, respectively. Panel (d) and (e) show the amplitude of ouabain-induced oscillations dose-dependently, and relative effect of SEA (0.01-1 $\mu \mathrm{M})$ on oscillations against control. Data in panel $d$ and e are expressed as mean \pm S.E.M, $(n=6-8)$. The significant change against control $(p<0.01)$ was shown by asterisk. The stimulation frequency was $1 \mathrm{~Hz}$.

\section{Effects of SEA on the ouabain-induced transient inward current $\left(I_{\mathrm{TI}}\right)$ or NCX current $\left(I_{\mathrm{NCX}}\right)$}

The underlying current behind the ouabain-induced oscillation, seen between action potentials (Fig 6a), was measured by current clamp method. The oscillation as shown in Fig. 6a was induced by $100 \mu \mathrm{M}$ of ouabain. In control condition all major current (Fig 6b), such as sodium current, calcium current and potassium currents, were observed and an inward current was observed at time $400-800 \mathrm{~ms}$ (Fig 6c) that is considered as transient inward current $\left(I_{\mathrm{TI}}\right)$ or NCX current $\left(I_{\mathrm{NCX}}\right)$. SEA $(1 \mu \mathrm{M})$ completely abolished this inward current (Fig 6d) without interfering other currents. 
a

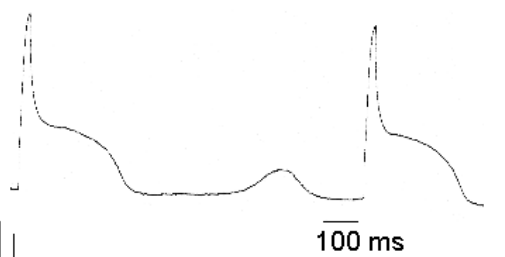

b
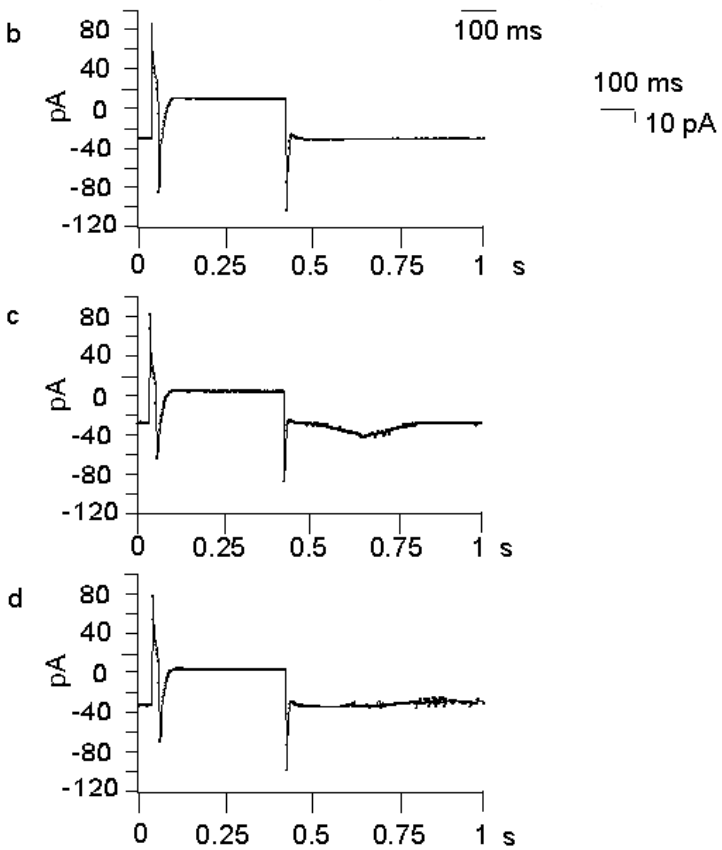

Fig. 6. Effects of SEA on ouabain-induced transient inward current $\left(I_{\mathrm{TI}}\right)$ or NCX current $\left(I_{\mathrm{NCX}}\right)$ in single ventricular myocytes recorded by current clamp and voltage-clamp methods. Panel (a) shows ouabain-induced oscillation between action potential stimulated by $1 \mathrm{~Hz}$. Panel (b), (c) and (d) show control, ouabain-induced NCX current and effect of SEA $(1 \mu \mathrm{M})$, respectively. The concentration of ouabain was $100 \mu \mathrm{M}$.

\section{Discussion}

Ouabain-induced arrhythmias in the whole animals, or oscillatory activity in between action potential configurations in isolated ventricular myocytes was used to study antiarrhythmic effects of drugs in dog, guinea pig, cat, sheep, and rat models [3, 11-14]. In the whole animal models, ouabain induces various types of ventricular tachyarrhythmias such as PVC, VT and VF. In the single ventricular myocyte model, ouabain induces oscillations in between action potential configurations which was observed between evoked action potentials [15] and these oscillations are thought to be caused by intracellular $\mathrm{Ca}^{2+}$ overload resulting in delayed after-depolarization (DAD). The inhibition of $\mathrm{Na}^{+}-\mathrm{K}^{+}$-ATPase by ouabain leads to a rise in $\left[\mathrm{Na}^{+}\right]_{\mathrm{i}}$ level which is also augmented by entry of the sodium ion into the cell by $\mathrm{Na}^{+}$-channels, $\mathrm{Na}^{+}-\mathrm{H}^{+}$pump and forward mode $\left(\mathrm{Ca}^{2+}\right.$ exit mode) of NCX. This increased intracellular $\mathrm{Na}^{+}$must be 
extruded from the cell. The major way of extrusion is the reverse mode $\left(\mathrm{Ca}^{2+}\right.$ entry mode) of NCX. Thus, the increased $\left[\mathrm{Na}^{+}\right]_{\mathrm{i}}$ level triggers the reverse mode $\left(\mathrm{Ca}^{2+}\right.$ entry mode) of NCX and favors entry of $\mathrm{Ca}^{2+}$ into the cell in exchange of $\mathrm{Na}^{+} \cdot \mathrm{Ca}^{2+}$ also enters into the cell by $\mathrm{Ca}^{2+}$-channels causing overload of $\left[\mathrm{Ca}^{2+}\right]_{\mathrm{i}}$ which is taken up and stored in SR. After the saturation of $\mathrm{SR}, \mathrm{Ca}^{2+}$ is oscillatorilly released through the $\mathrm{SR} \mathrm{Ca}^{2+}$-release channels (calcium induced calcium release, $\{\mathrm{CICR}\}$ ). The continued increase of $\mathrm{Ca}^{2+}$ is extruded out of the cell in exchange of $\mathrm{Na}^{+}$by forward mode $\left(\mathrm{Ca}^{2+}\right.$ exit mode) of NCX and produces $\mathrm{Ca}^{2+}$ oscillation by $\mathrm{Ca}^{2+}$ release from SR. The $\mathrm{Ca}^{2+}$ oscillation then induces $\mathrm{Na}^{+}$influx (or, increases net positive charge) through the forward mode $\left(\mathrm{Ca}^{2+}\right.$ exit mode) of NCX. These $\mathrm{Ca}^{2+}$ oscillation forms an ionic current component identified as transient inward current $\left(\mathrm{I}_{\mathrm{TI}}\right)$ [1-2, 16-17]. $\mathrm{I}_{\mathrm{TI}}$ induces oscillatory depolarization and when the membrane potential reaches above threshold, voltage gated $\mathrm{Na}^{+}$channels are activated, resulting in the generation of an action potential. If the membrane does not depolarize enough to make a complete action potential, it appears as DAD. In the whole animals these DAD cause triggered cardiac arrhythmias [18-19]. It is, thus, expected that NCX inhibitors would block ouabain-induced arrhythmias and oscillatory activity in the whole animals, or, in isolated ventricular myocytes.

In our whole animal experiments arrhythmias such as PVC, VT and VF were observed after intravenous injection of ouabain. From the above-mentioned cellular and molecular point of view, when sufficient amount of ouabain is present in the circulation, those DAD lead to extrasystoles and induce cardiac arrhythmias (triggered activity type) with rise and fall of arterial blood pressures as shown from the tracings of ECG in Figs. 2a-h. SEA $(1-10 \mathrm{mg} / \mathrm{kg})$ concentration-dependently decreased the duration of those arrhythmias (Fig. 4) with no appearance of most lethal form of arrhythmia, the VF, in both pre- and posttreatment. These results indicate that SEA is potent enough to inhibit the ouabain-induced arrhythmias in the whole guinea pigs.

While SEA has been reported to be a potent and selective NCX inhibitor [20-21, 27], its specificity and selectivity to NCX are still in question. Reuter et al. [22] indicated the possibility that SEA might interact with other transport systems, because SEA depressed the $\mathrm{Ca}^{2+}$ transients even in the mouse heart cells in which NCX was knocked out. In our study, ouabain (in the concentration range of 1-100 $\mu \mathrm{M}$ ) induced oscillatory activity (clinically looking like DAD) with different amplitudes in a concentration- dependentmanner (Fig. 5d) and SEA was effective in suppressing these activities (Fig. 5e) dosedependently. The dose range of ouabain $(1-100 \mu \mathrm{M})$ we used is not too toxic to the myocytes, because we used a moderate dose of ouabain $(10 \mu \mathrm{M})$ for the usual experiments but there is report of use of higher dose $(250 \mu \mathrm{M})$ by other investigators [23]. These results may indicate that SEA inhibits the forward mode $\left(\mathrm{Ca}^{2+}\right.$ exit mode) of $\mathrm{NCX}$, because the oscillatory activity (depolarization) was generated due to the rapid extrusion of $\mathrm{Ca}^{2+}$ in exchange of extracellular $\mathrm{Na}^{+}$through forward mode $\left(\mathrm{Ca}^{2+}\right.$ exit mode) of NCX. The IC $_{50}$ value of SEA for suppressing oscillatory activity (DAD) was calculated to be $75 \pm 3 \mathrm{nM}$ in our experiments and SEA at this concentration appears to be potent enough to block at least the forward mode $\left(\mathrm{Ca}^{2+}\right.$ exit mode) of NCX. 
In the current clamp and voltage clamp experiments, ouabain induced the NCX current $\left(I_{\mathrm{NCX}}\right)$ or transient inward current $\left(\mathrm{I}_{\mathrm{TI}}\right)$ (Fig. 6c) and SEA $(1 \mu \mathrm{M})$ abolished this NCX current $\left(I_{\mathrm{NCX}}\right)$ or transient inward current $\left(\mathrm{I}_{\mathrm{TI}}\right)$ (Fig. 6d) indicating that SEA selectively inhibited NCX currents in isolated ventricular myocytes of guinea pigs.

The selectivity of SEA on the different (forward and reverse) modes of NCX has also been disputed. SEA inhibited the outward NCX current (reverse mode or $\mathrm{Ca}^{2+}$ entry mode of NCX) in guinea pig ventricular cells with $\mathrm{IC}_{50}$ value of $40 \mathrm{nM}$ and inhibited the inward current (forward mode or $\mathrm{Ca}^{2+}$ exit mode of NCX ) with the value of $32 \mathrm{nM}$, indicating that the selectivity on the modes is less significant for SEA to inhibit NCX. This is also because SEA $(1 \mu \mathrm{M})$ inhibited both mode of NCX current by about $80 \%$ [21]. Matsuda et al. [20] have reported that SEA inhibited $\mathrm{Na}^{+}$-dependent ${ }^{45} \mathrm{Ca}^{2+}$ uptake (reverse mode or $\mathrm{Ca}^{2+}$ entry mode of NCX) in cultured neurons, astrocytes and microglia with $\mathrm{IC}_{50}$ value of 5-33 nM and did not estimate the value for the forward mode $\left(\mathrm{Ca}^{2+}\right.$ exit mode) of NCX. Recently, Lee et al. [23] studied the inhibitory profile of SEA on the cardiac NCX (NCX1.1) expressed in Xenopus laevis oocytes with the giant excised patch clamp technique. They reported that SEA inhibited outward NCX currents (reverse mode or $\mathrm{Ca}^{2+}$ entry mode) with high affinity ( $\mathrm{IC}_{50} \mathrm{~s}=78 \pm 15 \mathrm{nM}$ and $23 \pm 4 \mathrm{nM}$ for peak and steady state currents, respectively) and a less inhibitory potency $(\sim 8 \mu \mathrm{M})$ was observed for the inward current (forward mode or $\mathrm{Ca}^{2+}$ exit mode of NCX ). Our $\mathrm{IC}_{50}$ value $(75 \pm 3 \mathrm{nM}$ ) is close to that of Tanaka et al. [21] who showed $\mathrm{IC}_{50}$ value of $40 \mathrm{nM}$ and $32 \mathrm{nM}$ for reverse mode or $\mathrm{Ca}^{2+}$ entry mode and the forward mode or $\mathrm{Ca}^{2+}$ exit mode of NCX.

As the experimental conditions (such as ionic directions, e.g. unidirectional/ bidirectioal; method of induction of arrhythmias/ischemia) are one of the major determinants of the mode selectivity of NCX inhibitors, further study might be necessary to solve this question. The limitation of our study is that our $\mathrm{IC}_{50}$ value $(75 \pm 3 \mathrm{nM}) \mathrm{might}$ represent the $\mathrm{IC}_{50}$ value only for the forward mode $\left(\mathrm{Ca}^{2+}\right.$ exit mode of NCX), and it might be valid only for the pathologic or arrhythmic conditions, and it should not be extrapolated to the values in other experimental conditions.

In both of our in vivo and in vitro experiments, the potent and selective NCX inhibitor, SEA, completely suppressed ouabain-induced ventricular arrhythmias (Fig. 4), oscillatory activity (Figs. 5c and 5e) and $I_{\mathrm{NCX}}\left(I_{\mathrm{TI}}\right)$ (Fig. 6d) concentration-dependently and with no appearance of most lethal form of arrhythmias, the VF. Those results indicate that the role of NCX is important in the triggered activity type arrhythmias and oscillations induced by ouabain. A paper from our laboratory indicated that in in vivo canine model, digitalis (ouabain)-induced tachyarrhythmias were obviously suppressed by SEA (3 mg/kg) due to inhibition of NCX system by it [24]. But this result is inconsistent with a previous report from our laboratory in which KB-R7943 (KBR), another NCX inhibitor, did not suppress the digitalis-induced arrhythmia in the same model [12]. The opposite effects of the two different NCX inhibitors on digitalis-induced tachyarrhythmias may be explained by other independent effects of the two agents on cardiac ion channels or transporters. Because there is ample possibility that these agents can interact with other transport systems [2122]. Watano et al. [3] found that the intravenous injection of KBR, another NCX inhibitor, 
significantly increased the doses of ouabain required to induce ventricular arrhythmias (PVC, VT and VF) in anesthetized guinea pigs. They concluded that KBR could suppress ouabain-induced arrhythmias through inhibition of NCX. In a study it was showed that SEA0400 fails to alter the magnitude of intracellular $\mathrm{Ca}^{2+}$ transients and contractions in Langendorff-perfused guinea pig heart [26]. Another study suggest that complex changes in the $\mathrm{Ca}^{2+}$ cycling can occur after selective pharmacological inhibition of the $\mathrm{Na}^{+} / \mathrm{Ca}^{2+}$ exchanger [28]. A more recent study showed that pharmacological dissection of $\mathrm{I}_{\mathrm{NCX}}$ by using SEA0400 shows that $I_{\mathrm{NCX}}$ contributes significantly to the inward current during phases 3 and 4 of the AP [29].

The suppression of ouabain-induced arrhythmias and oscillatory activity by SEA indicate that both NCX and SR are involved in those activities. Suppression of either NCX or SR is enough to inhibit arrhythmias or oscillatory activity. We conclude that the ouabain-induced arrhythmia and oscillatory activities are induced by $\mathrm{Ca}^{2+}$ overload, and SEA might be used as an antiarrhythmic agent because it inhibited the NCX system in both isolated cardiac myocytes and anesthetized guinea pigs.

\section{Abbreviations Used}

$\left[\mathrm{Ca}^{2+}\right]_{\mathrm{i}}$ : intracellular $\mathrm{Ca}^{2+}$ concentration; DMSO: dimethylsulphoxide; ECG: electrocardiogram; $\left[\mathrm{Na}^{+}\right]_{\mathrm{i}}$ : intracellular $\mathrm{Na}^{+}$concentration; SR: sarcoplasmic reticulum; VF: ventricular fibrillation; VT: ventricular tachycardia; SEA0400: 2-[4-[(2,5-difluorophenyl)methoxy]phenoxy]-5-ethoxyaniline.

\section{References}

1. W. J. Lederer, and R. W. Tsien, J. Physiol. (London) 263, 73 (1976). PMid:1018270 PMCid:1307691

2. J. Kimura, S. Miyake, and A. Noma, J. Physiol. (London) 384,199 (1987). PMid:2443659 PMCid:1192258

3. T. Watano, Y. Harada, K. Harada, and N. Nishimaru, Br. J. Pharmacol. 127, 1846 (1999). http://dx.doi.org/10.1038/sj.bjp.0702740

4. G. Isenberg and U. Klockner, Pflugers Arch. 395, 6 (1982). http://dx.doi.org/10.1007/BF00584963

5. N. Homma, A. Hirasawa, K. Shibata, K. Hashimoto, and G. Tsujimoto, Br. J. Pharmacol. 129, 1113 (2000). http://dx.doi.org/10.1038/sj.bjp.0703179

6. M. S. Amran, N. Homma, and K. Hashimoto, J. Pharmacol Exp Ther. 310, 83 (2004). http://dx.doi.org/10.1124/jpet.104.066951

7. O. P. Hamil, A. Marty, B. Neher, B. Sakmann, and F. J. Sigworth, Plungers Arch.391, 85 (1981). http://dx.doi.org/10.1007/BF00656997

8. S. Wallestein, C. L. Zucker, and J. L. Fleiss, Circ Res. 47, 1 (1980). PMid:7379260

9. S. C. Dennis, D. J. Hearse, D. J. Coltart, Eur. J. Cardiol. 12,15 (1980). PMid:7439230

10. K. P. Pfeiffer and T. Kenner, Basic Res. Cardiol. 78, 239 (1983). http://dx.doi.org/10.1007/BF01907434

11. S. J. McGarry and A. J. Williums, Br. J. Pharmacol. 108, 1043 (1993). PMid:8387382 PMCid:1908139

12. S. Miyamoto, B. M. Zhu, K. Kamiya, Y. Nagasawa, and K. Hashimoto, Jpn. J. Pharmacol. 90, 229 (2002). http://dx.doi.org/10.1254/jip.90.229

13. S. R. Ruch, M. Nishio, J. A. Wasserstrom, J. Pharmacol Exp. Ther. 307, 419 (2003). http://dx.doi.org/10.1124/jpet.103.049189

14. L. S. Borda, B. Orman, S. Reina, and E. Enriborda, Biochem. Pharmacol. 66, 1871 (2003). http://dx.doi.org/10.1016/S0006-2952(03)00554-9 
15. M. S. Amran, N. Homma, and K. Hashimoto, Jpn J Pharmacol. 88, 260P (2002).

16. J. C. Khatter, M. Agbanyo, R. J. Hoeschen, S. Navaratnam, and R. Bains, J pharmacol Exp Ther. 239, 206 (1986). PMid:3020231

17. J. C. Khatter, M. Agbanyo, S. Navaratnam, B. Nero, and R. J. Hoeschen, Basic Res. Cardiol. 84, 553 (1989). http://dx.doi.org/10.1007/BF01906941

18. R. S. Kass, W. J. Lederer, R. W. Tsien, and R. Weingart, J Physiol. (London) 281,187 (1978). PMid:702368 PMCid:1282691

19. W. G. Wier and P. Hess, J. Gen. Physiol. 83, 395 (1984). http://dx.doi.org/10.1085/jgp.83.3.395

20. T. Matsuda, N. Arakawa, K. Takuma, Y. Kishida, Y. Kawasaki, M. Sakaue, K. Takahashi, T. Takahashi, T. Suzuki, T. Ota, A. Hamano-Takahashi, M. Onishi, Y. Tanaka, K. Kameo, and A. Baba, J. Pharmacol. Exp. Ther. 298, 249 (2001). PMid:11408549

21. H. Tanaka, K. Nishimaru, T. Aikawa, W. Hirayama, Y. Tanaka, and K. Shigenobu, Br. J. Pharmacol. 135, 1096 (2002). http://dx.doi.org/10.1038/sj.bjp.0704574

22. H. Reuter, S. A. Henderson, T. Han, T. Matsuda, A. Baba, R. S. Ross, J. I. Goldhaber, and K. D. Philipson, Circ. Res. 91, 90 (2002). http://dx.doi.org/10.1161/01.RES.0000027529.37429.38

23. C. Lee, N. Visen, N. S. Dhalla, H. D. Le, M. Isaac, P. Choptiany, G. Gross, A. Omelchenko, T. Matsuda, A. Baba, K. Takahashi, M. Hnatowich, and L. V. Hryshko, J. Pharmacol. Exp. Ther. 311 (2), 748 (2004). http://dx.doi.org/10.1124/jpet.104.070805

24. Y. Nagasawa, B.M. Zhu, J. Chen, K. Kamiya, S. Miyamoto, K. Hashimoto, Eur. J Pharmacol. 506, 249 (2005). http://dx.doi.org/10.1016/j.ejphar.2004.11.011

25. K. Takahashi, T. Takahashi, and T. Suzuki, Eur. J. Pharmacol. 458, 155 (2003). http://dx.doi.org/10.1016/S0014-2999(02)02732-2

26. S. Norbert, B. Péter, S. Gyula, F. Attila, M. János, T. András, C. László, V. András, and P. N. Péter, Naunyn-Schmiedeberg's Arch Pharmacol. 378, 65 (2008). http://dx.doi.org/10.1007/s00210-008-0296-5

27. Z. A. Nagy, L. Virág, A. Tóth, P. Biliczki, K. Acsai, T. Bányász, P. Nánási, J. G. Papp, and A. Varró, Br. J. Pharmacol. 143 (7), 827 (2004). http://dx.doi.org/10.1038/sj.bjp.0706026

28. K. Acsai, A. Kun, A. S. Farkas, F. Fülöp, N. Nagy, M. Balázs, N. Szentandrássy, P. P. Nánási, J. G. Papp, A. Varró, and A. Tóth, Eur. J. Pharmacol. 8, 576 (1-3), 1 (2007).

29. T. Banyasz, B. Horvath, Z. Jian, L.T. Izu, Y. Chen-Izu, Heart Rhythm. [Aug 30, Epub ahead of print] (2011). 